\title{
Expanded obsidian as a soil aerator, its porosity, physical and mechanical characteristics
}

\author{
Artsruni Safaryan ${ }^{1}$, Tamara Sarkisyan ${ }^{1}$, Tatevik Paytyan ${ }^{1}{ }^{*}$, Marine Kalantaryan ${ }^{1}$, and \\ Armine Baghdagyulyan ${ }^{1}$ \\ ${ }^{1}$ National University of Architecture and Construction of Armenia, 105 Teryan Street, 0009. \\ Yerevan, Republic of Armenia
}

\begin{abstract}
Today, the decline in soil fertility progress, therefore, special attention paid to the search for new, including non-traditional sources of raw materials that allow cultivating agricultural crops. It is propose to use expanded obsidian as a soil aerator. Obsidian is a volcanic rock, consisting of volcanic glass in which water content does not exceed 1\%. A characteristic feature of this stone is the ability to expand under heat treatment. The expansion of obsidian is possible to implement at temperatures of $1050 \ldots 1150^{\circ} \mathrm{C}$. It has been shown that due to obsidian expansion it is possible to obtain a light porous filler with an average density of $200 \ldots 350 \mathrm{~kg} / \mathrm{m}^{3}$, where the heat treatment of $5 \ldots 10 \mathrm{~mm}$ grains should be performed under temperatures from 1050 to $1150^{\circ} \mathrm{C}$, during 3 ...5 minutes. The mechanical strength of the expanded obsidian is due to the thickness of the internal partitions of the pores and depends on the total porosity. Increased porosity decreases the strength of the expanded obsidian grains as the internal partitions of the pores become thinner. Relatively high mechanical strength develop grains with less porosity, ie lower coefficient of expansion. At the same time, the nature of the external surface of the grain has a significant influence on the mechanical strength. The melted surface,under other equal conditions provides mechanical strength increase of the expanded obsidian.
\end{abstract}

\section{Introduction}

Obsidian is a volcanic rock consisting of volcanic glass in which the water content does not exceed $1 \%$. A characteristic feature of this stone is the ability to expand under heat treatment [1-4].

The expansion of obsidian is possible to implement at temperatures of $1050 \ldots 1150{ }^{\circ} \mathrm{C}$. It has been shown that due to obsidian expansion it is possible to obtain a light porous filler with an average density of $200 \ldots 350 \mathrm{~kg} / \mathrm{m}^{3}$, where the heat treatment of $5 \ldots 10 \mathrm{~mm}$ particles should be performed under temperatures from 1050 to $1150{ }^{\circ} \mathrm{C}$, during $3 \ldots .5$ minutes. The studies revealed that in order to obtain obsidian with high expansion coefficient or with low medium density $\left(200 \ldots 350 \mathrm{~kg} / \mathrm{m}^{3}\right)$, it is necessary to expand grains

\footnotetext{
* Corresponding author: paytyantatevik@gmail.com
} 
with particle sizes from 5 to $20 \mathrm{~mm}$ under $1050 \ldots 1150^{\circ} \mathrm{C}$, through burning, during $3 \ldots 5$ minutes. Expanded obsidian is a porous glassy mass, where the pores are separated by partitions (fig. 1).

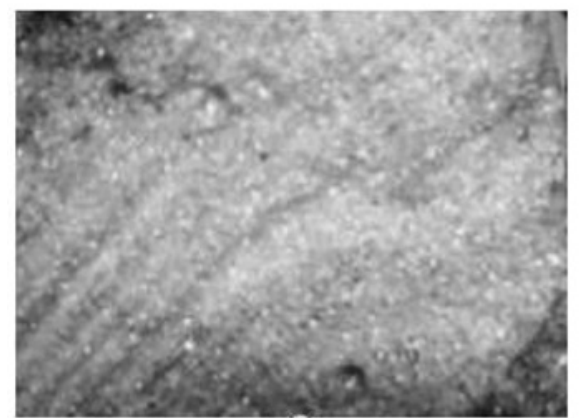

a)

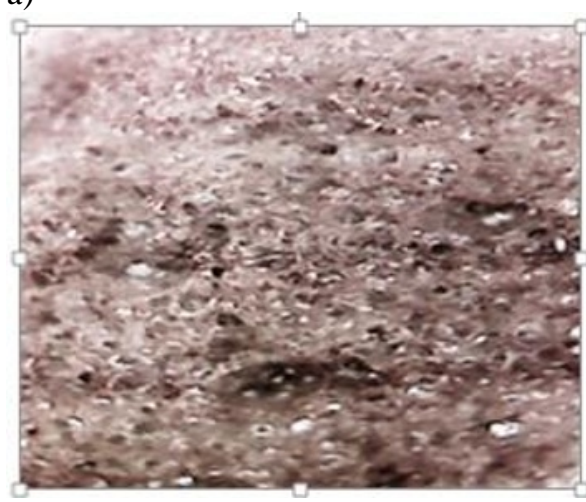

c)

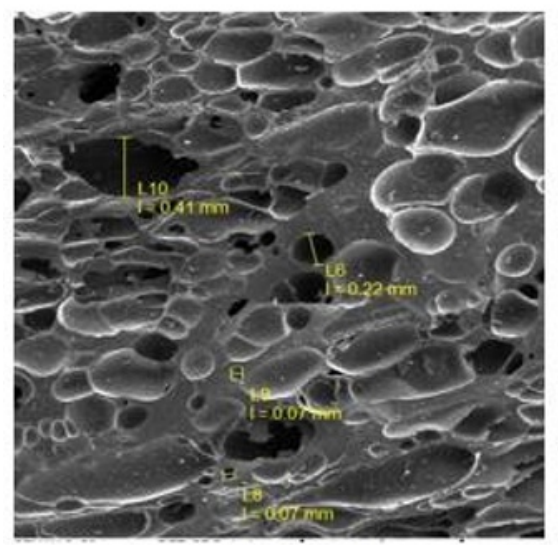

e)

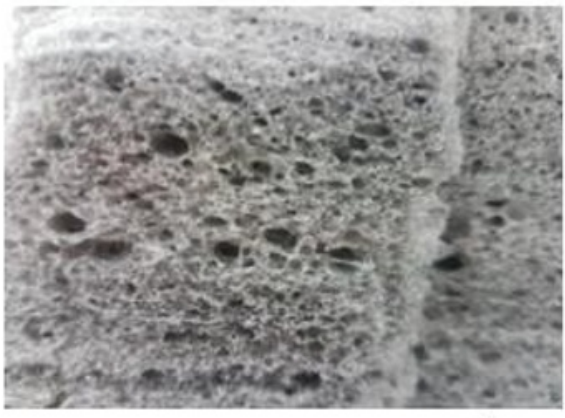

b)

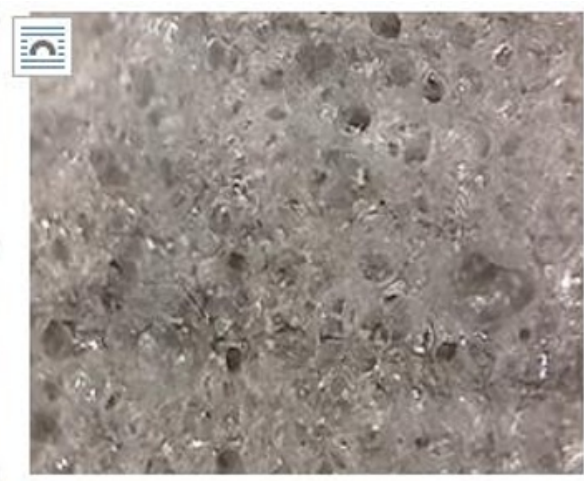

d)

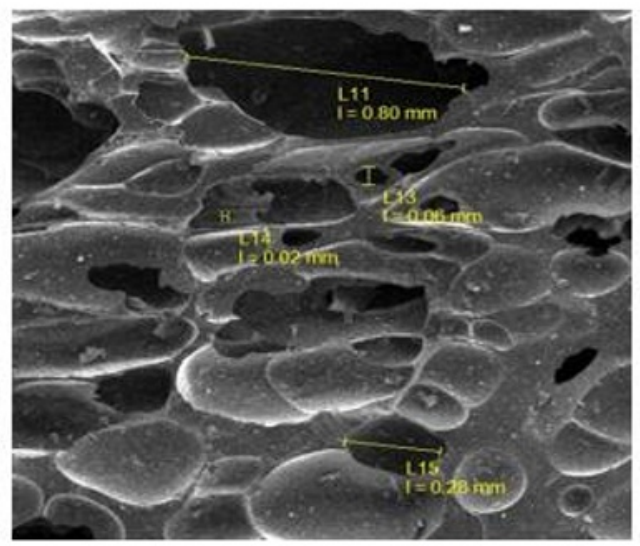

f)

Fig. 1. Porosity of expanded obsidian. a) the image of the expanded obsidian grain; b) magnified 25fold; c) magnified 200-fold; d) magnified 250-fold, e) the electron microscope image of 5.0... $10 . \mathrm{mm}$ particles, the pore sizes are from 0.07 to $0.41 \mathrm{~mm}, \mathrm{f}$ ) the electron microscope image of $10 \ldots$ $20 . \mathrm{mm}$ particles with porosity of $0.80 \ldots 0.02 \mathrm{~mm}$.

The thickness of the intercalations is irregular, some unexpanded parts of obsidian are noticed. The pores are spherical, mostly closed. There are two types of pores, large ones, surrounded by thick partitions. small particles that are distributed inside the glass. 
The impression is that the large pores were formed later than the small pores, and they cause deformations with their sizes.

Vast majority of pores are closed. The total porosity of expanded obsidian is $85 \ldots 90 \%$,

The quantity of interconnected pores is fluctuating from 10 to $25 \%$, and the quantity of open pores is $8 \ldots 20 \%$ :

The pores are spherical, the large sizes are $0.4 \ldots 0.8 \mathrm{~mm}$, the small ones are $0.02 \ldots 0.2$ $\mathrm{mm}$, the sizes of big partitions are $0.02 \ldots 0.6 \mathrm{~mm}$, and the small ones are $0.01 \ldots 0.05 \mathrm{~mm}$.

The mechanism of the expansion process can be represented as follows: at $1050 \ldots 1150$ ${ }^{\circ} \mathrm{C}$ the glass is softened, and at certain points, a relatively high elasticity of gas is formed, resulting in the formation of cells and consequently the expansion of the viscous mass.

The pyroplastic state of the glass is characterized by two features - viscosity and surface tension. The successful combination of these features has a decisive impact on the process of expansion. The expanding gases in the mass of heated glass (water vapor, $\mathrm{CO}_{2}$, etc.) generates high pressure, overcoming the particle cohesion forces (depending on the viscosity of the mass) and expands the material.

Concurrently the viscosity resistance, gases also tend to overcome the surface tension forces that attenuate and reduce the surface area of the resulting cell. The favorable pyroplastic state is characterized by a certain relationship between viscosity and surface tension forces.

The viscosity of the melt determines the strength of the pores. The higher the viscosity, the stronger the walls can withstand the pressure. Depending on the magnitude of the surface tension forces, the required pressure of the gas in the pores. Thus, these two characteristices mainly determine the structure of the porous material obtained: the formation of closed or open pores. The optimum conditions for the pyroplastic state are the high viscosity of the melt in case of low surface tension [5-11].

Obsidian expansion up to pyroplastic state is due to the formation of a liquid phase in the mineral melt. In this case, the viscosity decreases sharply, the gas phase pressure increases, creating an excess pressure sufficient to overcome the viscosity of the melt and to overcome the surface tension forces.

Based on the above mentioned facts, three stages of obsidian expansion can be described:

1. Obsidian expansion process during heat treatment of the material to the pyroplastic state due to the formation of a liquid phase in the mineral melt. In this case, the viscosity decreases, the gas phase pressure increases, creating an excess pressure sufficient to overcome the viscosity of the melt and to overcome the surface tension forces.

2. Gases in the pores of glass, primary (magmatic) and secondary (hydrate) waters participate in the process of expansion. The released gas phase is water vapor.

3. Maximum approximation of the mass of the pyroplastic state and the gaseous phase release is the most important factor in determining the efficiency of the expanding process.

4. The mechanism of silicate melt expanding is possible to represent by the dependence between the pressure and the physical and chemical parameters of the melt. The presented ideas about the expanding mechanism indicate that the expanding material should have closed pores. The gases in the pores during the expansion increase approximately $4 \ldots 5$ times with the increase of the temperature. [5-11].

\section{Methodology}

It follows fromafore-cited that the expanding process should be adjusted so, as to maximize the intensive gas formation and optimum pyroplastic states to the moments of mass softening. In particular, it is necessary to take into account the size of the glass expanding 
particles, which determines the temperature gradient of the grain edges and internal central parts.

At high temperatures, the surface of the glass grains rapidly melts, the resulting external layer makes difficulties to release gases.

The duration of obsidian at high temperatures depends on the size of the particles, and therefore, different particle sizes should be subjected to different heat treatment conditions to obtain the required bulk and medium density of materials.

The mechanical strength of the expanded obsidian is primarily due to the thickness of the internal partitions of the pores and depends on the overall porosity.

The dependence of the expanded obsidian strength on porosity in presented in the table. The results revealed that the increased porosity decreases the strength of obsidian grains as they penetrate into the internal pores. Relatively high mechanical strength exhibit the grains with less porosity, ie lower coefficient of expansion.

At the same time, the mechanical strength is strongly influenced by the nature of the internal surface of the particle, and the melted surface provides, under other equal conditions an increase in the mechanical strength of the expanded obsidian.

The obtained physical and mechanical characteristics are presented in the Table.

Table 1. Physical and mechanical characteristics of expanded obsidian.

\begin{tabular}{|c|c|c|l|c|c|c|c|}
\hline № & $\begin{array}{l}\text { Grain } \\
\text { sizes, } \mathrm{mm}\end{array}$ & $\begin{array}{l}\text { Average } \\
\text { density, } \\
\mathrm{kg} / \mathrm{cm}^{3}\end{array}$ & $\begin{array}{l}\text { Average } \\
\text { bulk } \\
\text { density, } \\
\mathrm{kg} / \mathrm{cm}^{3}\end{array}$ & $\begin{array}{l}\text { Compressive } \\
\text { strength (in } \\
\text { piece) } \\
\mathrm{MPa}\end{array}$ & $\begin{array}{l}\text { Porosity, } \\
\%\end{array}$ & $\begin{array}{l}\text { Water } \\
\text { absorption, } \\
\text { (mass) }\end{array}$ & $\begin{array}{l}\text { Mass loss } \\
\text { after testing } \\
\text { freeze } \\
\text { resistance } \\
\% \text { (mass) }\end{array}$ \\
\hline 1 & 2 & 3 & 4 & 5 & 6 & 7 & 8 \\
\hline 1. & $+40 \ldots$. & 220 & 180 & 4.5 & 89 & 15,5 & 3,4 \\
\hline 2. & $40 \ldots 20$ & 280 & 230 & 4.7 & 88 & 15,2 & 3,2 \\
\hline 3. & $20 \ldots 10$ & 330 & 280 & 5.0 & 87 & 15,0 & 2,8 \\
\hline 4. & $10 \ldots 5$ & 350 & 290 & 5.5 & 86 & 14,0 & 2,7 \\
\hline 5. & $5 \ldots 2.5$ & 390 & 340 & 8.6 & 80 & 13,0 & 2,3 \\
\hline
\end{tabular}

Such a low loss of the expanded obsidian mass after frost resistance testing is explained by the fact that the amount of open pores varies from 8 to $12 \%$. Due to the compressed air in the pores and capillaries, a space remains where the formed ice crystals during the cooling processes expand and therefore exhibit substantially low pressure on the partitions of pores.

\section{Conclusion}

By studying the physical and mechanical parameters of the expanded obsidian, it was found that the water absorption varies depending on the expansion coefficient, nature and size of the internal surface. In the case of high expanding coefficient, water absorption increases, and the melted surface decreases. The mechanical strength of the expanded obsidian particles depends on the thickness of the pores and the shape of the surface.

In case of high expansion coefficient, the strength decreases, however, the grains with melted surfaces are stronger. The expanded obsidian is considered to be freeze resistant because after 15 cycles of testing the mass loss does not exceed 5\%. The results of complex studies of physical and mechanical characteritics indicate that the expanded obsidian can be fully used as a lightweight concrete filler. 


\section{References}

1. Geology, exploration technique and technology. Digest of articles (Gosgeoltekhizdat, Moscow, 1962)

2. S.P. .Komenetsky, State production committee for installation and special construction works of the USSR (All-Union Scientific Research and Design Institute „Teploproekt,, Moscow, 1963)

3. V.V. Nasedkin, V.P. Petrov, Perlites (Pub. Science, Moscow, 1981)

4. A.I. Augustnik, Physical chemistry of silicates (Stroyizdat, Moscow, 19669

5. P. Ayler, Chemistry of silica (Publ. Mir, Moscow, 1982)

6. G.S. Burlakov, Basics of ceramics and artificial porous fillers technology (Higher school, Moscow, 1972)

7. B.V. Vinogradov, Petrography of artificial porous fillers (Constpub, Moscow, 1972)

8. B.V. Deryagin, Surface forces (Science, Moscow, 1985)

9. G.S. Zhdanov, Physics of solid material (Metallurgy, Moscow, 1987)

10. A.A. Zhukovski, L.A. Shvartsman, Physical chemistry (Metallurgy, Moscow, 1987)

11. V. Israelyan, R. Mkhitaryan, Mat. Of X Inf. Cort on the Physics of Noncrystalline Solids 82-84 (2003) 